\title{
Evaluation and Counseling of Candidates
}

\author{
Enric Carreras and Alessandro Rambaldi
}

\subsection{Evaluation of Candidates and Risk Factors for HSCT}

Enric Carreras

\subsubsection{Introduction}

The evaluation of candidates and the analysis of individual risk factors for HSCT permit to establish four fundamental aspects:

1. The HSCT indication

2. To inform the patient properly

3. To choose the best donor, conditioning, and post-HSCT IS

4. To evaluate the results of the transplant in large series

E. Carreras

Spanish Bone Marrow Donor Registry,

Josep Carreras Foundation and Leukemia Research

Institute, Barcelona, Catalunya, Spain

Hospital Clinic Barcelona, Barcelona University,

Barcelona, Spain

A. Rambaldi $(\bowtie)$

Department of Hematology-Oncology,

Azienda Socio Sanitaria Territoriale Papa Giovanni

XXIII, Bergamo, Università Statale di Milano,

Milano, Italy

e-mail: alessandro.rambaldi@unimi.it

\subsubsection{Candidates' Evaluation Work Flow}

\subsubsection{First Visit}

The most relevant aspects to take into account in this first visit are:

- Medical history (past and present) and physical examination (see Sect. 11.1.2.4).

- Review of diagnostic tests (in referred patients).

- Revaluate HLA typing of patient and potential donors (if allo-HSCT).

- Preliminary information on:

- Therapeutic options and results

- HSCT procedure

- Possible complications and side effects (see specific chapters in Part V)

- Schedule reevaluation of the current status of the disease (see Sect. 11.1.3).

- Schedule visits with radiation therapist (if TBI), dentist, gynecologist, blood bank (list of blood/platelet donors), HSCT unit supervisor nurse, etc.

- Signature of the informed consent for HSCT and for procurement of HSC (if auto-HSCT).

\subsubsection{Visit Preharvesting} (Auto-HSCT)

- Assess the results of complementary explorations.

- Complete information on the procedure. 
- If PBSC, assess the status of venous accesses. Program CVC (if necessary) and mobilization schedule.

- If BM: preanesthetic visit.

- Program manipulation of HSCT (if applicable) and/or cryopreservation.

\subsubsection{Last Visit Before Admission}

- Final and complete patient information (see Sect. 11.1.2.5).

- Evaluate reevaluation studies performed (see Sect. 11.1.3).

- Schedule admission and conditioning treatment.

- If necessary, program CVC placement.

- If allo-HSCT: confirm that the donor's evaluation is correct and there are no contraindications for donation (see Chap. 12).

- If auto-HSCT: confirm that the cryopreserved cellularity is correct.

- Submit donor and recipient information to the blood bank (group, CMV serology, previous transfusions, etc.).

- If TBI: confirm that the dosimetry has been carried out and the RT has been programmed.

- Confirm storage of patient and donor samples for serotheque and cellular library.

\subsubsection{Medical History}

Collect information on:

Medical background; childhood illnesses and vaccines; allergies and adverse drug reactions; surgical interventions (previous anesthesia); medications not related to the basic process; previous transfusion history, family tree, and family history valuable; in women, menarche/menopause, pregnancy and childbirth, contraceptive methods, date last rule, and gynecological checkups

Travel to malaria, trypanosomiasis, and HTLV-I/II endemic areas

Previous relevant infections

Data about the current illness:

- Start date and initial symptomatology

- Diagnostic methodology used (staging)

- Chemotherapy and radiotherapy treatments (doses and dates)

- Complications from such treatments

- Result of these treatments

- Recurrences and their treatment
- Transfusions received

- Current state of the disease

Social aspects

- Smoking, alcoholism, and other drug use

- Sexual habits

- Availability of accommodation close to the center and means of transport

- Support family members

- Ethnic, cultural, and intellectual aspects

\subsubsection{Information to Provide (See Detailed Information in Counseling Section)}

Ask the patient (privately) which escorts he or she wishes to have present in this session. For adolescents follow the rules of each country respecting the right of information. Transmit as much information as possible in writing. She/he must be informed about:

- Most frequent early and late complications (see specific chapters in Parts V and VI) including graft failure, GI complications, alopecia, SOS/ VOD, acute GVHD, early infections, chronic GVHD, late infections, relapse of the disease, infertility, endocrine complications, neoplasms, and other secondary.

- Treat specifically serious complications (ICU admissions) and possibility of death. Inform about the advance directive registry. Agreeing with the patient on an interlocutor in case at some point they may not be able to make decisions.

- Estimated duration of admission, approximate day of admission.

- Most frequent complications on discharge, outpatient follow-up, likelihood of readmission, and need for caregivers at discharge.

\subsubsection{Complementary Explorations}

All the following studies must be performed within 30 days prior to the HSCT except the assessment of baseline disease status (7-15 days) and the pregnancy test (7 days):

- $\mathrm{CBC}$ and basic coagulation; complete biochemistry (including ferritin); blood type and 
Rh/irregular antibodies; dosage of Igs; serology CMV, EBV, VHS, VVZ, toxoplasma, syphilis, HBsAg, HBcAb, and anti-HBsAb (HTLV-I/II, and Chagas disease according to the patient's origin); NAT for HCV, HBV, and HIV; pregnancy test

- Chest X-ray; respiratory function tests (including FEV1 and DLCO); electrocardiogram; echocardiogram or isotopic ventriculography (depending on previous treatment)

- Reevaluation of the disease (MRD) (see specific chapters in part IX)

- Dental evaluation; gynecological evaluation; psychological/psychiatric evaluation

- Nutritional assessment

- HLA typing (recheck) (see Chap. 9)

\subsubsection{Risk Assessment}

\subsubsection{Individual Risk Factors}

There are a group of variables that have a prognostic value in all predictive models

\begin{tabular}{|c|c|}
\hline Variables & High risk \\
\hline Age & $\begin{array}{l}\text { Older. Do not use as a single } \\
\text { criterion. Relative importance }\end{array}$ \\
\hline General condition & Karnofsky index $<80 \%$ \\
\hline Disease & $\begin{array}{l}\text { Not in remission. See specific } \\
\text { chapters }\end{array}$ \\
\hline Type of donor & $\begin{array}{l}\text { Others than HLA-identical } \\
\text { siblings }\end{array}$ \\
\hline HLA compatibility & $\begin{array}{l}\text { Any HLA-A, HLA-B, HLA-C, } \\
\text { and DRB1 difference }\end{array}$ \\
\hline CMV serology & Different serology than the donor \\
\hline Donor & $\begin{array}{l}\text { Age }>35-40 \text { years } \\
\text { For male recipient, female donor } \\
\text { (especially if multiparous) }\end{array}$ \\
\hline $\begin{array}{l}\text { Interval } \\
\text { diagnosis-HSCT }\end{array}$ & $\begin{array}{l}\text { Prolonged (relevant in CML and } \\
\text { SAA) }\end{array}$ \\
\hline Comorbidities & See HCT-CI model \\
\hline Iron overload & Present \\
\hline $\begin{array}{l}\text { Experience of the } \\
\text { center }\end{array}$ & $\begin{array}{l}\text { Non-JACIE/FACT accredited } \\
\text { centers }\end{array}$ \\
\hline
\end{tabular}

\subsubsection{Predictive Models}

\section{Disease Risk Index (DRI) (Armand et al.} 2012, 2014)

Prognostic index based in the disease and its status at HSCT. It doesn't take into account factors as age or comorbidities. This score index classi-
Table 11.1 Disease risk index (Armand 2012, 2014)

\begin{tabular}{|c|c|c|c|}
\hline Risk & \multicolumn{3}{|l|}{ Disease } \\
\hline Low & \multicolumn{3}{|c|}{$\begin{array}{l}\text { AML with favorable cyt., CLL, CML, } \\
\text { indolent B-cell NHL }\end{array}$} \\
\hline Intermediate & \multicolumn{3}{|c|}{$\begin{array}{l}\text { AML intermediate cyt., MDS } \\
\text { intermediate cyt., myeloproliferative } \\
\text { neoplasms, MM, HL, DLBCL/ } \\
\text { transformed indolent B-NHL, MCL, } \\
\text { T-cell lymphoma nodal }\end{array}$} \\
\hline High & \multicolumn{3}{|c|}{$\begin{array}{l}\text { AML adverse cyt, MDS adverse cyt, } \\
\text { T-cell lymphoma extranodal }\end{array}$} \\
\hline Risk & \multicolumn{3}{|c|}{ Stage } \\
\hline Low & \multicolumn{3}{|c|}{$\begin{array}{l}\mathrm{CR} 1, \mathrm{CR} \geq 2, \mathrm{PR} 1 \text {, untreated, CML CP, } \\
\mathrm{PR} \geq 2 \text { (if } \mathrm{RIC} \text { ) }\end{array}$} \\
\hline High & \multicolumn{3}{|c|}{$\begin{array}{l}\mathrm{PR} \geq 2 \text { (if } \mathrm{MAC} \text { ), induction failure, active } \\
\text { relapse, CML AP or BP }\end{array}$} \\
\hline Disease risk & Stage risk & Overall risk & OS at 4 years \\
\hline Low & Low & Low & $\begin{array}{l}64 \% \\
(56-70 \%)\end{array}$ \\
\hline Low & High & \multirow[t]{2}{*}{ Intermediate } & $46 \%$ \\
\hline Intermediate & Low & & $(42-50 \%)$ \\
\hline Intermediate & High & \multirow[t]{2}{*}{ High } & $26 \%$ \\
\hline High & Low & & $(21-31 \%)$ \\
\hline High & High & Very high & $6(0-21 \%)$ \\
\hline
\end{tabular}

Adapted from Armand (2012). Cyt. cytogenetics

fies the disease in four prognostic groups and anticipates overall survival, progression-free survival, cumulative incidence of relapse, and cumulative incidence of non-relapse mortality (see Table 11.1).

EBMT Risk Score (Gratwohl et al. 1998, 2009)

This predictive score, validated with 56,505 patients, permits to predict approximately the 5-year probability of OS and the TRM for the main diseases (see Tables 11.2, 11.3, and 11.4).

EBMT risk score is also useful to predict OS and TRM in patients receiving a second HSCT (Rezvani et al. 2012) and in those receiving a TCD HSCT (Lodewyck et al. 2011).

Some authors have introduced modifications in this risk score (including the concept of disease stage) to improve its predictivity (Terwey et al. 2010; Hemmati et al. 2011). Similarly, it has been associated with the HCT-CI (Barba et al. 2014).

This score has been validated by many groups and for many diseases (AML, ALL, PMF, CLL, and CML, among others). 
Table 11.2 EBMT risk score (Gratwohl 2009)

\begin{tabular}{|c|c|c|}
\hline Variables & Value of variables & Points \\
\hline \multirow[t]{3}{*}{ Age } & $<20$ years & 0 \\
\hline & 20-40 years & 1 \\
\hline & $>40$ years & 2 \\
\hline \multirow[t]{3}{*}{ Disease status $^{\mathrm{a}}$} & Early & 0 \\
\hline & Intermediate & 1 \\
\hline & Advanced & 2 \\
\hline \multirow{2}{*}{$\begin{array}{l}\text { Interval } \\
\text { diagnosis-HSCT }\end{array}$} & $<12$ months & 0 \\
\hline & $\geq 12$ months & 1 \\
\hline \multirow[t]{2}{*}{ Donor } & $\begin{array}{l}\text { HLA-identical } \\
\text { sibling }\end{array}$ & 0 \\
\hline & Unrelated donor & 1 \\
\hline \multirow{2}{*}{$\begin{array}{l}\text { Gender } \\
\text { donor - recipient }\end{array}$} & Female to male & 1 \\
\hline & Other combinations & 0 \\
\hline
\end{tabular}

Adapted from Gratwohl (2009)

aDo not apply in patients with SAA. Early = AL in CR1; MDS in CR1 or untreated; CML in 1st chronic phase; NHL/MM untreated or in CR1. Intermediate $=\mathrm{AL}$ in CR2; CML in other status than accelerated phase or blastic phase; MDS in CR2 or in PR; NHL/MM in CR2, PR, or stable dis. Late $=\mathrm{AL}$ in other stages; $\mathrm{CML}$ in blastic crisis; MDS in all other stages; NHL/MM in all other stages ${ }^{b}$ Do not apply to patients in CR1

Table 11.3 Probability (\%) of TRM at 5 years applying the EBMT risk score

\begin{tabular}{|l|c|c|c|c|c|c|c|}
\hline Points & 0 & 1 & 2 & 3 & 4 & 5 & $6-7$ \\
\hline AML & 14 & 20 & 25 & 30 & 36 & 40 & 41 \\
\hline ALL & 15 & 23 & 24 & 30 & 40 & 47 & 53 \\
\hline CML & 15 & 22 & 30 & 38 & 45 & 52 & 55 \\
\hline AA & 18 & 26 & 40 & 49 & 52 & & \\
\hline MDS & 25 & 28 & 30 & 35 & 38 & 46 & 50 \\
\hline MM & & & 29 & 35 & 40 & 42 & 52 \\
\hline NHL & 15 & 24 & 28 & 30 & 34 & 36 & 38 \\
\hline
\end{tabular}

Extracted from Gratwohl (2009)

Table 11.4 Probability (\%) of OS at 5 years applying the EBMT risk score

\begin{tabular}{|l|c|c|c|c|c|c|c|}
\hline Points & 0 & 1 & 2 & 3 & 4 & 5 & $6-7$ \\
\hline AML & 68 & 59 & 52 & 38 & 30 & 23 & 18 \\
\hline ALL & 66 & 52 & 43 & 38 & 22 & 16 & 14 \\
\hline CML & 76 & 72 & 60 & 51 & 39 & 26 & 14 \\
\hline AA & 81 & 72 & 60 & 49 & 45 & & \\
\hline MDS & 56 & 52 & 46 & 40 & 35 & 28 & 25 \\
\hline MM & & & 48 & 40 & 36 & 22 & 17 \\
\hline NHL & 75 & 59 & 50 & 48 & 43 & 40 & 38 \\
\hline
\end{tabular}

Extracted from Gratwohl (2009)

\section{HCT-Comorbidity Index (HCT-CI) (Sorror} et al. 2005)

Developed in Seattle in 2005. It is an adaptation to the HSCT of the classical Charlson Comorbidity Index (CCI). Validated in several cohorts and widely used. The score analyzes 17 comorbidities as well as their degree (see Table 11.5).

Given the impact of age on outcomes, the authors modified the model (Sorror et al. 2014), including a 1-point score for patients aged 40 . This modification significantly improved the predictive capacity of the model. Consequently, the patients could be classified in three different risk groups ( 0 points, low risk; $1-2$ points, intermediate risk; 3 or more, high risk) that clearly correlated with 2-year NRM.

Other authors re-stratified the HCT-CI index (flexible HCT-CI) as low risk, 0-3 points; intermediate risk, $4-5$ points; and high risk, $>5$ points, being this classification a better predictor for NRM. In RIC setting, the 100-day and 2-year NRM incidence in these risk categories was $4 \%$, $16 \%$, and $29 \%$ and $19 \%, 33 \%$, and $40 \%$, respectively. They do find this predictive NRM value using neither the original HCT-CI nor the PAM or CCI models. Regarding the 2-year OS, this flexible HCT-CI score was also associated with the highest predictive hazard ratio (Barba et al. 2010).

HCT-CI has also been validated in CD34+ selected HSCT (Barba et al. 2017) and associated with the EBMT risk score that permits a better stratification (Barba et al. 2014).

\section{Pretransplantation Assessment of Mortality (PAM) Score (Parimon et al. 2006; Au et al. 2015)}

Developed in Seattle in 2006 but underused and poorly validated. It combines eight variables from patients and HSCT. Only useful for assessing mortality at 2 years.

Variables included age, type of donor, risk of disease, intensity of conditioning, DLCO, FEV1, creatinine, and ALT.

\section{EBMT Machine Learning Algorithm}

(Shouval et al. 2015)

Based in an alternating decision tree able to detect variables associated with the primary 
Table 11.5 HSCT-comorbidity index including age variable (Sorror 2005, 2014)

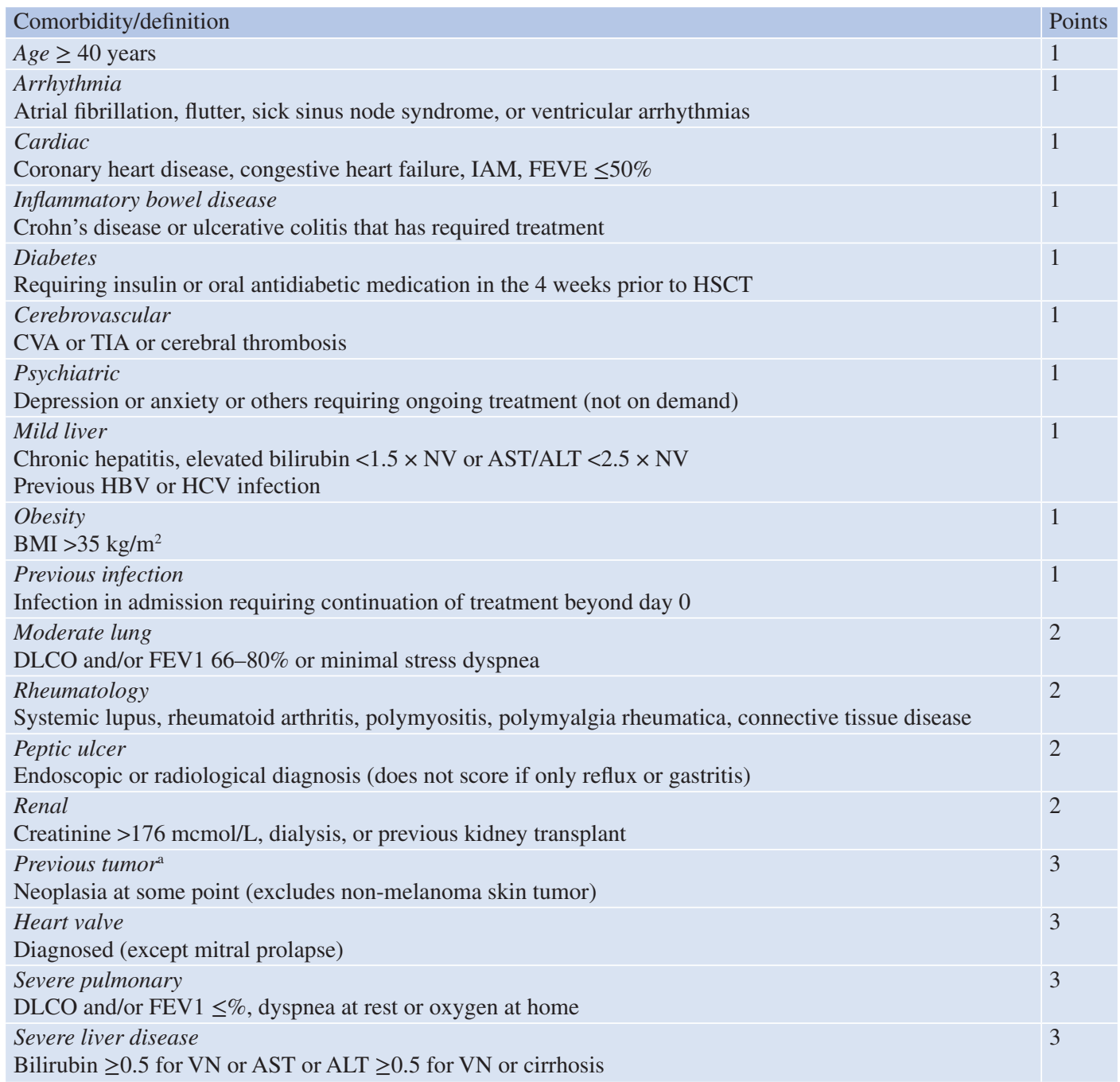

${ }^{\mathrm{a}} \mathrm{A}$ most recent version also includes in this category hematological/tumors of a different lineage to that which motivates the transplant (e.g., lymphoma in an AML patient but not previous MDS in AML patient)

outcome, assigning weights and ignoring redundancies. This score was developed to analyze the NRM at day +100 in patients with acute leukemia but also predict NRM, LFS, and OS at 2 years.

The variables included in the model are age, Karnofsky $(\geq 80 ;<80)$, diagnostic (AML; ALL), disease stage (CR1; CR2; all other stages), interval diagnostic-HSCT ( $<142$ days; $\geq 142$ days), donor-recipient CMV status (both (sero +); both (sero -); any other combination), donor type (MSD; MUD), conditioning (MAC; RIC), and annual allo-HSCT performed in the center $(<20$; $\geq 21$ ). The total $+100 \mathrm{NRM}$ and 2-year NRM, LFS, and OS could be obtained through a web page: http://bioinfo.lnx.biu.ac.il/ bondi/web1. html.

Recently this algorithm has also been validated by an independent set of data from GITMO (Shouval et al. 2017).

\subsubsection{Predictive Capacity of These Models}

Unfortunately, all these models have a relatively low predictive capacity, and none of them stand out more than the rest. 


\begin{tabular}{l|l|l|} 
Author & $\begin{array}{l}\text { Predictive/s } \\
\text { model/s }\end{array}$ & $\begin{array}{l}\text { Predictive } \\
\text { capacity }\end{array}$ \\
$\begin{array}{l}\text { Sorror et al. } \\
\text { (2005) }\end{array}$ & HCT-CI & 0.65 \\
$\begin{array}{l}\text { Xhaard (2008) } \\
\text { Gratwohl (2009) }\end{array}$ & rHCT-CT, PAM & $0.49,0.57$ \\
$\begin{array}{l}\text { Barba et al. } \\
(2010)\end{array}$ & fHCT-CI, PAM & 0.63 \\
\hline $\begin{array}{l}\text { Barba et al. } \\
(2014)\end{array}$ & HCT-CI, EBMT & $0.67,0.63$ \\
\hline $\begin{array}{l}\text { Versluis (2015) } \\
\text { (HCT-CI-EBMT) }\end{array}$ & $0.58,0.58(0.64)$ \\
\hline
\end{tabular}

Courtesy of P. Barba, MD. rHCT-CI = reduced model, without PFTs; fHSCT $=$ flexible model (modified scale)

\subsubsection{Practical Applications of Risk Assessment}

\begin{tabular}{l|l}
$\begin{array}{l}\text { Election of the } \\
\text { conditioning }\end{array}$ & $\begin{array}{l}\text { In patients with a high risk of NRM } \\
\text { following one of the mentioned risk } \\
\text { scores, a RIC should be considered }\end{array}$ \\
$\begin{array}{l}\text { Relative } \\
\text { contraindications }\end{array}$ & $\begin{array}{l}\text { Uncontrolled infection, severe or } \\
\text { chronic liver disease (excluding } \\
\text { cirrhosis), severe disturbances in } \\
\text { heart function }(\mathrm{FEV}<40 \%), \\
\text { respiratory (DLCO }<40 \%) \text { or renal } \\
\text { (creatinine clearance }<30 \mathrm{~mL} / \mathrm{min})\end{array}$ \\
\hline $\begin{array}{l}\text { Absolute } \\
\text { contraindications }\end{array}$ & $\begin{array}{l}\text { Pregnancy } \\
\text { Cirrhosis. Even compensated } \\
\text { cirrhosis receiving RIC have a high } \\
\text { likelihood of hepatic } \\
\text { decompensation (Hogan et al. } \\
\text { 2004) }\end{array}$
\end{tabular}

\section{Key Points}

- The evaluation of a candidate must be carried out according to a preestablished work plan designed by each institution. The use of standardized procedures reduces the risk of errors or omissions

- Several pretransplant variables (such as age) have a clear impact on the results of the procedure but, when assessed in isolation, are highly insufficient to predict the results

- Predictive models (DRI, EBMT risk score, HCT-CI, PAM) allow a much more realistic approach to the real possibilities of a given candidate and adapt the procedure to their needs

\subsection{Counseling of Candidates}

Alessandro Rambaldi

\subsubsection{Introduction}

Allo-HSCT is a potentially curative treatment modality for otherwise incurable diseases. Unfortunately, after transplantation patients may experience not only the persistence or recurrence of their own disease but also some dramatic clinical complications and toxicities, including death. The clinical indications to transplant have been addressed in the section "indications" of this book, but in general, when the allo-HSCT is advised, the strength of the indication (the likelihood to be cured by transplant), the patient fitness, and his/her personal commitment to transplant must be carefully evaluated for each candidate.

Obviously, a first distinction must be done between patients with a neoplastic versus a non-neoplastic disease, and the transplant option should be progressively discussed with the patient during the course of the disease, particularly in the case of hematologic malignancies. Many professionals should concur to illustrate the patients the curative potential of an allo-HSCT and to help understanding the severe complications that can eventually develop. It is clear that different indications remarkably affect the way a patient is advised. However, there is a time when the transplant option must be formally presented and advised. Therefore, evaluation of each transplant candidate must be based on well-predefined formal standard operating procedures to collect exhaustive clinical, instrumental, and laboratory data that may lead to a robust definition of the risks and benefits related to allo-HSCT. All in all, the counseling is to tailor such evaluation to the individual patients (Shouval et al. 2015), according to both objective data and subjective data such as patient propensity and fear of side effects. At the end of this process, the patient should be aware of the rationale, the 
benefit and the toxicity associated with each step, and component of the transplant procedure. In this chapter, I will hereby summarize the main topics I cover with my patients when they come to my office to discuss the option of the allo-HSCT.

\subsubsection{Understanding the Benefit and Risk of Allogeneic Transplant}

Patients must be informed that allo-HSCT is a therapeutic option that is always proposed with the intent to achieve a permanent cure of the underlying disease, but despite this premise, disease progression or relapse may eventually happen. The indication to allo-HSCT depends not only on the disease characteristics but also on patient-related factors such as age and comorbidities (Sorror et al. 2007) so that the transplant proposal is the result of an accurate and wise evaluation of both these factors (Sorror et al. 2013; Wang et al. 2014).

The patient should understand the specific risk/benefit balance associated with a conventional versus a transplant-based proposal, and this may be remarkably different if he has been diagnosed with a non-neoplastic disease such as thalassemia or sickle cell anemia, a bone marrow failure syndrome like aplastic anemia, or a blood cancer, such as an acute leukemia. Even when allo-HSCT may in theory represent the most efficacious treatment modality to get a permanent cure of a specific disease, an accurate description of the available alternatives must be presented. This is particularly important when the non-transplant options, albeit not curative, may have the chance to keep the patient alive for a long time (Samuelson Bannow et al. 2018) or, even more importantly, when the conventional treatment may lead to a definitive cure such as in the case of some patients with acute leukemia with intermediaterisk genetic factors or those achieving a deep molecular remission after conventional chemotherapy (Cornelissen and Blaise 2016).

\subsubsection{Understanding the Transplant Procedure: The Donor, the Conditioning Regimen, and the Clinical Complications}

Once the indication to transplant has been confirmed, patients and their relatives must be informed on how the transplant is performed. Patients should understand that identifying a stem cell donor is an absolute prerequisite to perform a transplant. Accordingly, patients should be informed about the human leukocyte antigen (HLA) genetic system, its specificity for each individual, how it is inherited by parents according to the Mendelian laws, and what is the probability to find a compatible donor in the family group. Understanding the HLA system is crucial to explain why the use of a HLA family-matched sibling donors is considered standard and when such a sibling is not available; an international search has to be performed to identify a HLA-compatible unrelated donor. It is important to underline that more than 30 million of potentially available donors are registered by the World Marrow Donor Association (WMDA), and the probability to find a compatible donor is between 50 and $80 \%$ according to the ethnical origin of each patient.

Once such matched unrelated donor is identified, this type of transplant is considered a standard of care, and its clinical outcome is fully comparable to what was observed when using an HLA-identical sibling. In patients for whom a MSD or a MUD is not available, the patient should be informed that two additional options are available, namely, the use of HSC obtained by a family mismatched donor (commonly defined as haploidentical because sharing only one of the patient's HLA haplotypes) or a banked cord blood units. Patients should understand how the HLA diversity between patient and donor has been overcome by specific programs of in vitro or in vivo manipulation of the graft.

Patients should be reassured that the incidence and severity of GvHD, the most important side effect of allo-HSCT, seems not to be higher than observed with MUD. In addition, patients should know that many single-arm studies reported that 
transplants performed with these alternative stem cell sources proved to be effective and safe even when offered to patients of advanced age and/or with existing accompanying illnesses or when the disease was refractory to conventional treatment. All in all, at the present time, the clinical outcome of these alternative types of transplants compares reasonably well with those achieved with MUD. Therefore, the decision to use this type of stem cell source only when an HLAmatched donor is not available is mostly related to the lack of randomized clinical trials that are planned to be performed in the near future.

The goal of an allo-HSCT is to eradicate the patient's hematopoiesis either neoplastic or normal. This is achieved by the delivery of the conditioning regimen and by the lifelong in vivo effect played by the donor's immune system. Most often, high doses of chemotherapy and/or radiation are included in the preparations although remarkable differences exist depending on the disease needing transplant and patient tolerance. The patient should understand that the intensity of the conditioning regimen may be particularly important in the case of hematologic malignancies when the aim to remove most of the neoplastic cells present in the patient's body is the first goal. However, to avoid at least part of the treatment toxicity, the intensity of the preparative regimen can be down-modulated leading to the definition of this preparative regimen as nonmyeloablative or reduced intensity. The depletion of the patient bone marrow stem cells induces a prolonged pancytopenia and the need of donorderived healthy stem cells to grow and establish a new blood cell production system.

The allogeneic HSC, collected from the donor's BM or PB or a frozen CBU, are infused through the central venous catheter into the bloodstream: HSCT is not a surgical procedure and it is very similar to receiving a blood transfusion. The stem cells find their way into the bone marrow and begin reproducing and growing new, healthy blood cells. It is very important to explain how the donor immune system will develop progressively after transplantation and will either exert a crucial beneficial role against residual neoplastic cells or restore the immune compe- tence against infections, but it could mediate the most harmful GvHD effect against the patient.

After the transplant, supportive care is given to prevent and treat infections, side effects of treatments, and complications. Prolonged anemia, thrombocytopenia, and leukopenia can be dangerous and even life-threatening. A low platelet count can be potentially associated with bleeding in the lungs, GI tract, and brain. Leukopenia, including either a defect of neutrophils and lymphocytes, leads to the development of frequent infections, the most common clinical complications after transplantation. Infections can include not only bacterial, most likely when the patient has a severe bone marrow suppression, but also viral and fungal pathogens. Infections can require an extended hospital stay, prevent or delay engraftment, and/or cause permanent organ damage. On average the time to hematologic engraftment (recovery of the neutrophil and platelet function) is about 2-3 weeks, but a protective recovery of the immune system can take months and sometimes years. High doses of chemotherapy and radiation can cause remarkable toxicities that include but not limited to severe mucositis (inflammation of the mouth and GI tract) that favors bacterial translocation with related infections and GvHD and multi-organ failure mainly the lung, heart, liver, and kidney.

A particular attention should be paid to risk of graft failure that can occur early or late after transplantation. A graft failure is more frequent in some diseases such as myelofibrosis or as the results of infections or when the stem cell content of the graft is insufficient to guarantee a durable engraftment. A graft rejection can also happen after reduced intensity conditioning regimen (when the immune system of the host is not completely eradicated and can actively reject the donor stem cells).

Finally, and most importantly, patients must be aware of what GvHD is, when and how it may develop, and why it represents the most serious complication of a HSCT, being not only lifethreatening but also the principal reason of a long-lasting poor quality of life. Transplant candidates should be aware that GvHD is the negative counterpart of the deep interaction of the donor immune system within patient body that at the same time may lead to definitive cure of an 
otherwise incurable disease. In other words, when transplant is advised, patients must realize that they are accepting the possible onset of a chronic, often invalidating, autoimmune disease. GVHD can appear at any time after transplant. GvHD is conventionally distinguished in an acute form that usually develops within the first 100 days after transplant and the chronic form that occurs later in the transplant course. Patients who develop acute GVHD are more likely to also develop the chronic form of GVHD. Patients must understand the importance of their compliance to all the treatments given post transplant to prevent GvHD and how this is instrumental for a successful transplant. GvHD occurs when the donor's immune system reacts against the recipient's tissue. At variance to what happens after a solid organ transplant where the patient's immune system is driven to reject only the transplanted organ, in GVHD, the donor immune system can react against many different organs of the recipient. This is why the new cells do not recognize the tissues and organs of the recipient's body as self. Over time, thanks to the effect of immune suppressive drugs, a progressive tolerance can develop. The most common sites for GVHD are the GI tract, liver, skin, and lungs.

\section{Key Points}

Counseling of patients should be carefully performed to inform candidates that:

- Disease and patient's specific characteristics are equally important to advise transplant

- Allo-HSCT is performed to cure otherwise incurable diseases

- Despite transplant, disease persistence or relapse may occur

- Transplant can severely compromise the quality of life of patients

- Transplant is a form of immunotherapy requiring long-term follow-up care

- Logistics are important to ensure adequate care and assistance

\subsubsection{Logistics}

After discharge for the transplant ward, patients are followed up in the outpatient clinic two to three times per week until day +100 . Patients should be helped to realize how complex is the transplant procedure and that the time spent in the hospital represents only the first part of the treatment program. All allo-HSCT patients should ideally stay within $1 \mathrm{~h}$ of the hospital until it is about 3 months from the day of the transplant. Patients and their families should also realize that the overall recovery time varies from person to person and in general this process takes about 1 year to be satisfactory. Allogeneic transplantation is therefore a long-lasting immunotherapy, and the interaction between the donor immune system and the patient requires a careful and prolonged medical assistance, quite often long life.

\section{References}

Armand P, Gibson CJ, Cutler C, et al. A disease risk index for patients undergoing allogeneic stem cell transplantation. Blood. 2012;120:905-13.

Armand P, Kim HT, Logan BR, et al. Validation and refinement of the disease risk index for allogeneic stem cell transplantation. Blood. 2014;123:3664-71.

$\mathrm{Au}$ BK, Gooley TA, Armand P, et al. Reevaluation of the pretransplant assessment of mortality score after allogeneic hematopoietic transplantation. Biol Blood Marrow Transplant. 2015;21:848-54.

Barba P, Piñana JL, Martino R, et al. Comparison of two pretransplant predictive models and a flexible HCT-CI using different cut off points to determine low-, intermediate-, and high-risk groups: the flexible HCT-CI Is the best predictor of NRM and OS in a population of patients undergoing allo-RIC. Biol Blood Marrow Transplant. 2010;16:413-20.

Barba P, Martino R, Pérez-Simón JA, et al. Combination of the hematopoietic cell transplantation comorbidity index and the European Group for blood and marrow transplantation score allows a better stratification of high-risk patients undergoing reduced-toxicity allogeneic hematopoietic cell transplantation. Biol Blood Marrow Transplant. 2014;20:66-72.

Barba P, Ratan R, Cho C, et al. Hematopoietic cell transplantation comorbidity index predicts outcomes in patients with acute myeloid leukemia and myelodysplastic syndromes receiving CD34(+) selected grafts for allogeneic hematopoietic cell transplantation. Biol Blood Marrow Transplant. 2017;23:67-74. 
Cornelissen JJ, Blaise D. Hematopoietic stem cell transplantation for patients with AML in first complete remission. Blood. 2016;127:62-70.

Gratwohl A, Hermans J, Goldman JM, et al. Risk assessment for patients with chronic myeloid leukaemia before allogeneic blood or marrow transplantation. Chronic Leukemia Working Party of the European Group for Blood and Marrow Transplantation. Lancet. 1998;352:1087-92.

Gratwohl A, Stern M, Brand R, et al. Risk score for outcome after allogeneic hematopoietic stem cell transplantation: a retrospective analysis. Cancer. 2009;115:4715-26.

Hemmati PG, Terwey TH, le Coutre P, et al. A modified EBMT risk score predicts the outcome of patients with acute myeloid leukemia receiving allogeneic stem cell transplants. Eur J Haematol. 2011;86:305-16.

Hogan WJ, Maris M, Storer B, et al. Hepatic injury after nonmyeloablative conditioning followed by allogeneic hematopoietic cell transplantation: a study of 193 patients. Blood. 2004;103:78-84.

Lodewyck T, Oudshoorn M, van der Holt B, et al. Predictive impact of allele-matching and EBMT risk score for outcome after T-cell depleted unrelated donor transplantation in poor-risk acute leukemia and myelodysplasia. Leukemia. 2011;25:1548-54.

Parimon T, Au DH, Martin PJ, Chien JW. A risk score for mortality after allogeneic hematopoietic cell transplantation. Ann Intern Med. 2006;144:407-14.

Rezvani K, Kanfer EJ, Marin D, Gabriel I, et al. EBMT risk score predicts outcome of allogeneic hematopoietic stem cell transplantation in patients who have failed a previous transplantation procedure. Biol Blood Marrow Transplant. 2012;18:235-40.

Samuelson Bannow BT, Salit RB, Storer BE, et al. Hematopoietic cell transplantation for myelofibrosis: the dynamic international prognostic scoring system plus risk predicts post-transplant outcomes. Biol Blood Marrow Transplant. 2018;24:386-92.

Shouval R, Labopin M, Bondi O, et al. Prediction of allogeneic hematopoietic stem-cell transplantation mortality 100 days after transplantation using a machine learning algorithm: a European Group for Blood and
Marrow Transplantation Acute Leukemia Working Party retrospective data mining study. J Clin Oncol. 2015;33:3144-51.

Shouval R, Bonifazi F, Fein J, et al. Validation of the acute leukemia-EBMT score for prediction of mortality following allogeneic stem cell transplantation in a multi-center GITMO cohort. Am J Hematol. 2017;92:429-34.

Sorror ML. How I assess comorbidities before hematopoietic cell transplantation. Blood. 2013;121:854-63.

Sorror ML, Maris MB, Storb R, et al. Hematopoietic cell transplantation (HCT)-specific comorbidity index: a new tool for risk assessment before allogeneic HCT. Blood. 2005;106:2912-9.

Sorror ML, Giralt S, Sandmaier BM, et al. Hematopoietic cell transplantation specific comorbidity index as an outcome predictor for patients with acute myeloid leukemia in first remission: combined FHCRC and MDACC experiences. Blood. 2007;110:4606-13.

Sorror ML, Storb RF, Sandmaier BM, et al. Comorbidityage index: a clinical measure of biologic age before allogeneic hematopoietic cell transplantation. J Clin Oncol. 2014;32:3249-56.

Terwey TH, Hemmati PG, Martus P, et al. A modified EBMT risk score and the hematopoietic cell transplantation-specific comorbidity index for pretransplant risk assessment in adult acute lymphoblastic leukemia. Haematologica. 2010;95:810-8.

Versluis J, Labopin M, Niederwieser D, et al. Prediction of non-relapse mortality in recipients of reduced intensity conditioning allogeneic stem cell transplantation with AML in first complete remission. Leukemia. 2015;29:51-7.

Wang HT, Chang YJ, Xu LP, Liu DH, Wang Y, Liu KY, Huang XJ. EBMT risk score can predict the outcome of leukaemia after unmanipulated haploidentical blood and marrow transplantation. Bone Marrow Transplant. 2014;49:927-33.

Xhaard A, Porcher R, Chien JW, et al. Impact of comorbidity indexes on non-relapse mortality. Leukemia. 2008;22:2062-9.

Open Access This chapter is licensed under the terms of the Creative Commons Attribution 4.0 International License (http://creativecommons.org/licenses/by/4.0/), which permits use, sharing, adaptation, distribution and reproduction in any medium or format, as long as you give appropriate credit to the original author(s) and the source, provide a link to the Creative Commons license and indicate if changes were made.

The images or other third party material in this chapter are included in the chapter's Creative Commons license, unless indicated otherwise in a credit line to the material. If material is not included in the chapter's Creative Commons license and your intended use is not permitted by statutory regulation or exceeds the permitted use, you will need to obtain permission directly from the copyright holder.

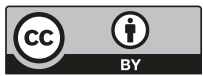

